\title{
TITLE; NUMERICAL ANALYSIS OF INTERLOCKING CAISSON BREAKWATER USING MODULAR SYSTEM
}

\author{
Sunghoon Song, Korea Institute of Civil Engineering and Building Technology, songsunghoon@kict.re.kr \\ Minsu Park, Korea Institute of Civil Engineering and Building Technology, mspark@kict.re.kr \\ Youngjun You, Korea Institute of Civil Engineering and Building Technology, yjyou@kict.re.kr \\ Younju Jeong, Korea Institute of Civil Engineering and Building Technology, yjjeong@kict.re.kr \\ Yoonkoog Hwang, Korea Institute of Civil Engineering and Building Technology, ykhwang@kict.re.kr
}

\section{INTRODUCTION}

Breakwaters have been severely damaged quite often since they are directly exposed to large waves. And damage level of breakwaters has been scaled up because of abnormal global climate changes. In particular, according to the report of caisson breakwater damages in Japan(Takayama, 2002), it was found that damages caused by caisson sliding, account for more than $70 \%$ of breakwater failure modes. So, the design criteria for new breakwaters is being intensified to cope with abnormal global climate changes and unusual waves. In the case of a long structure, the wave force is reduced due to the phase difference in oblique waves. Therefore, if a caisson is made as long as possible, the stability of breakwaters could be ensured even if unusual high waves occur. Recently, interlocking caisson systems, which are to form a long caisson by interlocking individual caissons with each other, have been much attention to enhance the structural stability of conventional caisson breakwaters. In the present study, a modular caisson was proposed that can improve structural stability and workability by using the shear-key interlocking system; and the wave force reduction effects of the modular caisson breakwater were evaluated by numerical analysis method.

\section{CONCEPT OF INTERLOCKING CAISSON}

In the interlocking caisson breakwater, it does not move independently because caissons are connected to adjacent caissons. When non-uniform wave forces due to the phase difference are exert on an interlocked long breakwater as shown in Figure 1, the total wave force can be averaged along the long breakwater alignment. Thus, the maximum wave force acting on one caisson can be reduced. In general, the reduction ratio of wave force depends on the caisson length $I$, the wave direction $\theta$, the wave length $L$, and the duration time of peak wave force. Therefore, in the interlocking caisson breakwater, it is possible to increase the caisson length I and the reduction ratio by interlocking caissons to each other.

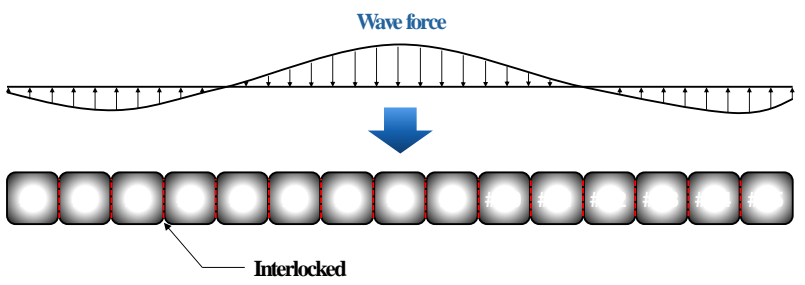

Figure 1 - Concept of interlocking caisson breakwater

\section{FEATURES OF MODULAR CAISSON}

Figure 2 shows the detailed shape and the features of the modular caisson interlocked by the shear-interlocking system. The each caisson units are interlocked to adjacent caissons by the shear-key on the side and bottom of the caisson in both the horizontal and vertical directions. As a result, it is possible to improve the stability of sliding and overturning of a caisson.

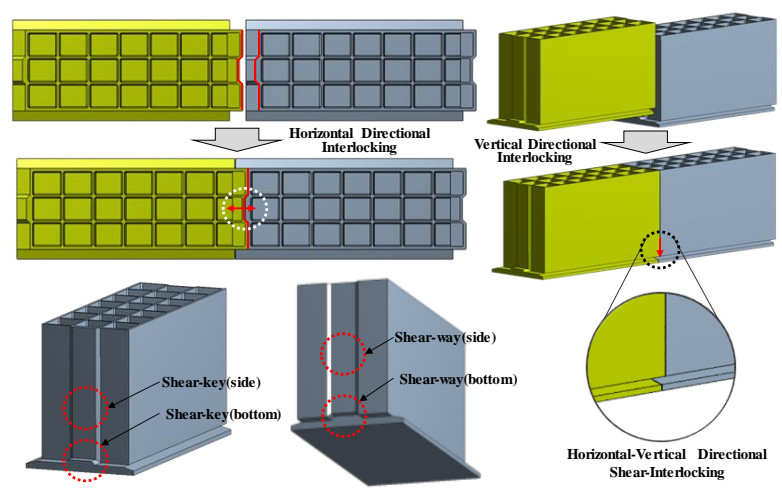

Figure 2 - Shape of the modular interlocking caisson

\section{NUMERICAL ANALYSIS}

The purpose of numerical analysis is to evaluate the wave force reduction effects by wave smoothing of the long caisson breakwater composed of the modular caisson. For this purpose, the numerical analysis were carried out with the commercial program ANSY. Figure 3 shows a full analysis model for the long caisson breakwater. It was assumed to consist of fifteen caisson units, and total length is $510 \mathrm{~m}$. As a result of comparing the reduction ratio of the wave force, the reduction effect at the incident wave angle of $30^{\circ}$ was relatively larger than one at the incident wave angle of $0^{\circ}$. As shown in Figure 4, it can be seen that the shorter the duration time and the greater the slope of the peak wave, the larger the wave reduction effect by wave smoothing.

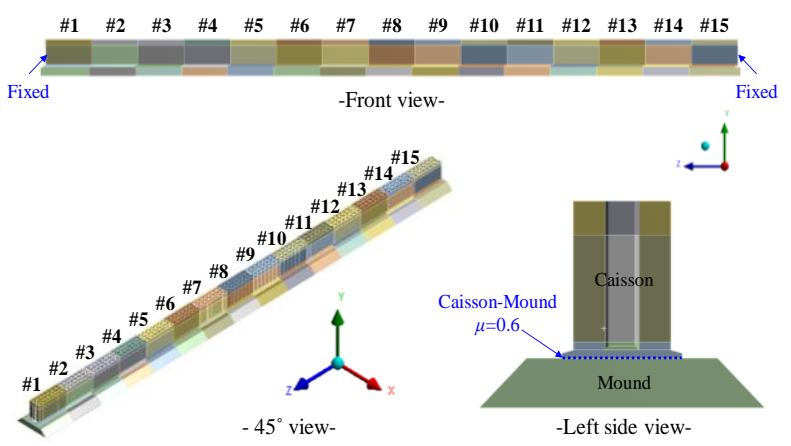

Figure 3 - Numerical analysis model
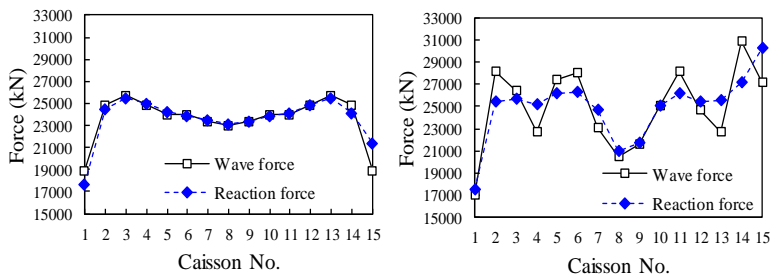

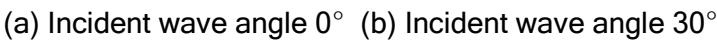

Figure 4 - Wave and Reaction force acting on a caisson 
The wave force reduction coefficient was also numerically evaluated for varying the number of caissons and the weight of one caisson, see figure 5. From the results of the analysis, the reduction coefficient was almost constant regardless of the number of caissons interlocked and its weight, and depends on the wave force acting on the caisson. In Figure 6 , the critical load $F_{\text {critical }}$ is the wave load at the time when the sliding of the non-interlocked caisson occurs. For example, if the wave ratio $F / F_{\text {critical }}$ is 1.4 , the reduction coefficient $\alpha$ and the ratio of the design wave force to the critical load $F_{a} / F_{\text {critical }}$ is 0.73 and 1.0 respectively.

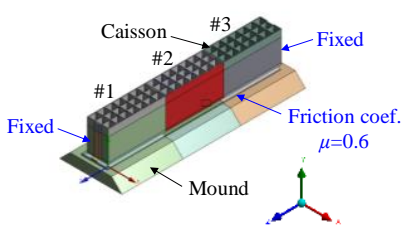

3-units

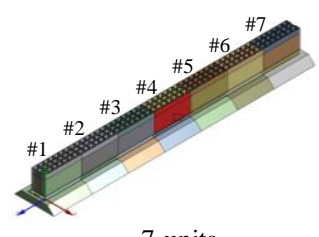

7-units
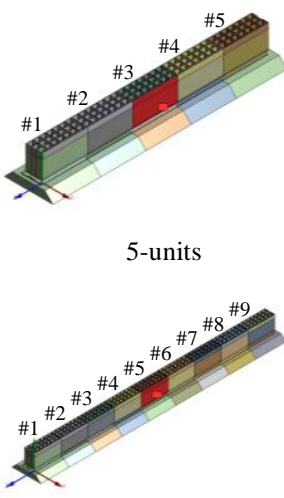

9-units
Figure 5 - Structural analysis model
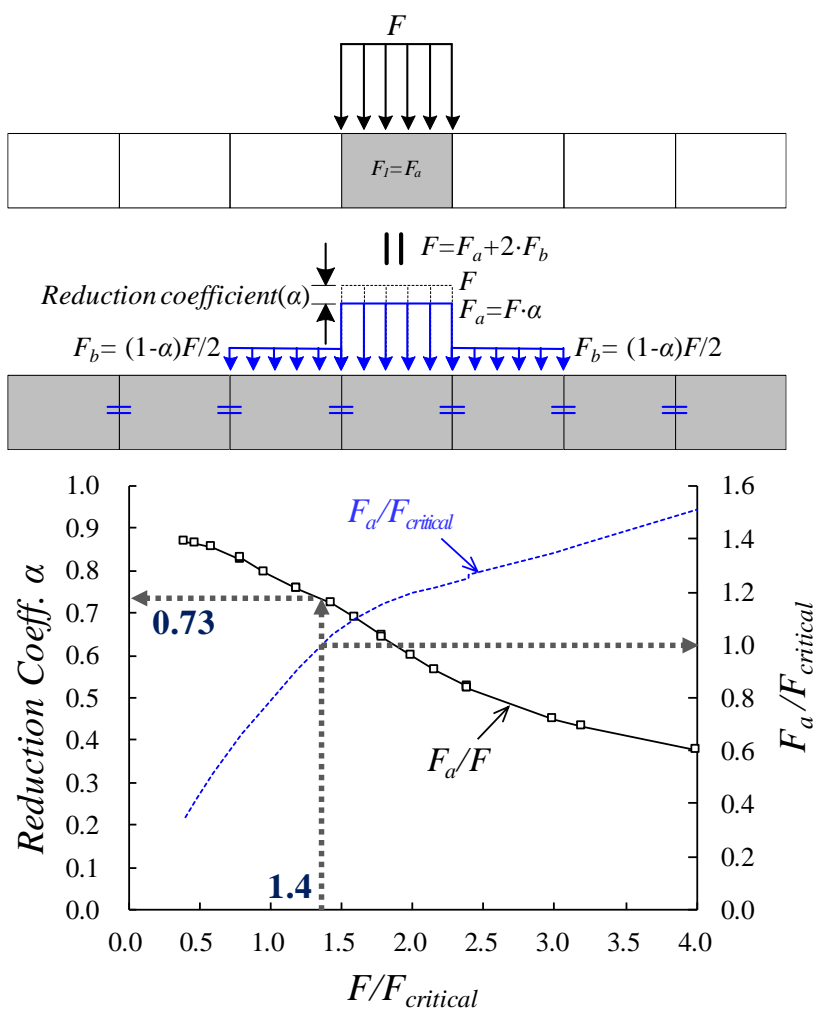

Figure 6 - Reduction coefficient of wave force

\section{CONCLUSIONS}

The wave force reduction effects of the modular caisson breakwater using the shear-key interlocking system have been evaluated numerically. The results obtained from the analysis results are as follows: (1) The reduction effect by wave smoothing is more effective when the duration of peak wave force is short and the variation of the wave force distribution per unit length acting on the interlocking caisson breakwater is large; (2) The wave force reduction coefficient depends on the magnitude of the wave force acting on the caisson, regardless of the number of caissons interlocked and the weight of one caisson.

\section{ACKNOWLEDGMENTS}

This work is part of the "Development of design and construction technologies of modular revetment structure(20160281)", a R\&D project of the Korea Institute of Marine Science \& Technology Promotion (KIMST) funded by the Korea Ministry of Maritime Affairs and Fisheries in 2016.

\section{REFERENCES}

Takahashi, Shimosako (1990): Reduction of wave force on a long caisson of vertical breakwater and its stability, Port and Harbour Research Institute, Technical Notes No. 685. Takayama, Higashira (2002): Statistical analysis on damage characteristics of breakwaters, Proc. of Ocean Development Conf., 18, pp. 263-268.

Kim, Lee, Park, Jung (2010): Making Long Caisson Breakwater Using Interlocking System, Journal of the Korean Society of Civil Engineers 58(12), pp. 65-71.

Park, Won, Seo (2016): An Interlocking Caisson Breakwater with Fillers, Journal of the Korean Society of Civil Engineers, 64(8), pp. 28-32. 